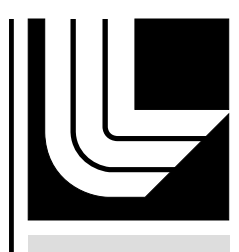

LAWRENCE LIVERMORE N A TIO NAL LABORATORY

\title{
Report on Simulations of the Royle-Sentoku-Fuchs Experiment
}

H. D. Shay

February 21, 2013 
This document was prepared as an account of work sponsored by an agency of the United States government. Neither the United States government nor Lawrence Livermore National Security, LLC, nor any of their employees makes any warranty, expressed or implied, or assumes any legal liability or responsibility for the accuracy, completeness, or usefulness of any information, apparatus, product, or process disclosed, or represents that its use would not infringe privately owned rights. Reference herein to any specific commercial product, process, or service by trade name, trademark, manufacturer, or otherwise does not necessarily constitute or imply its endorsement, recommendation, or favoring by the United States government or Lawrence Livermore National Security, LLC. The views and opinions of authors expressed herein do not necessarily state or reflect those of the United States government or Lawrence Livermore National Security, LLC, and shall not be used for advertising or product endorsement purposes.

This work performed under the auspices of the U.S. Department of Energy by Lawrence Livermore National Laboratory under Contract DE-AC52-07NA27344. 

H. D. Shay, LLNL
LLNL-TR-620154

A series of calculations have been performed to reproduce the experimental results presented by Royle at the Fast Ignition Workshop, November, 2012. This note summarizes the results of these simulations.

The calculations consist of coupling the hydro-radiation code HYDRA with the PIC code ZUMA. This combination tracked fast electrons in ZUMA for 500ps, linked the heating history to HYDRA, repeated the same 500ps period in HYDRA with the heating source, and then iterated back to ZUMA. The geometry roughly mocks up the experiment of two laser beams incident on a Au foil $30 \mu \mathrm{m}$ thick, as shown in figure 1. In a 2D approximation to two incident laser beams, electrons were injected in an annular beam, $10 \mu \mathrm{m}$ wide and with a mean radius of $21 \mu \mathrm{m}$. In ZUMA, the electrons are tracked in 3D velocity space. The electrons were given a ponderomotive birth distribution for a constant laser intensity of $510^{19} \mathrm{~W} / \mathrm{cm}^{2}$ for $1 \mu \mathrm{m}$ laser light, a conversion efficiency of $52 \%$, and a pulse length of $2 \mathrm{ps}$. The birth angular distribution of the electrons was a cone of half angle $50^{\circ}$. To match the experiment, the center of this cone would be inclined by $35^{\circ}$ (with respect to the normal to the target surface) toward the axis. In these simulations, a low density $\left(10^{-3} \mathrm{~g} / \mathrm{cc}\right)$ occupies the space behind the Au foil. As a diagnostic, the simulations had a thin $\mathrm{C}$ foil placed $20 \mu \mathrm{m}$ behind the rear surface of the Au; it would not have influenced the behavior in the Au foil.

Without any angle of inclination, the electron density, the $\mathrm{B}_{\theta}$ field, and the material temperature at the end of the laser pulse, $2 \mathrm{ps}$, are shown in figure 2 . By contrast, with the $35^{\circ}$ angle of inclination, the results are shown in figure 3 . The tendency of the electron beam to bunch on the axis is clearly much more pronounced with the $35^{\circ}$ angle of incidence. In fact, the centroid of the beam has moved at an angle of about $65^{\circ}$, much more than the $35^{\circ}$ given at launch.

There are rather large electric fields in the region of the beam focusing as indicated in figure 4 , with values in the well focused simulation of ZRAC typically greater than $410^{9} \mathrm{~V} / \mathrm{m}$. By contrast, the simulation with normal incidence (ZRAG) shows lower, less tightly concentrated electric field.

In short, these simulations show qualitatively the same focusing effect observed in the experiment. 
Report on Simulations of the Royle-Sentoku-Fuchs Experiment

Figure 1

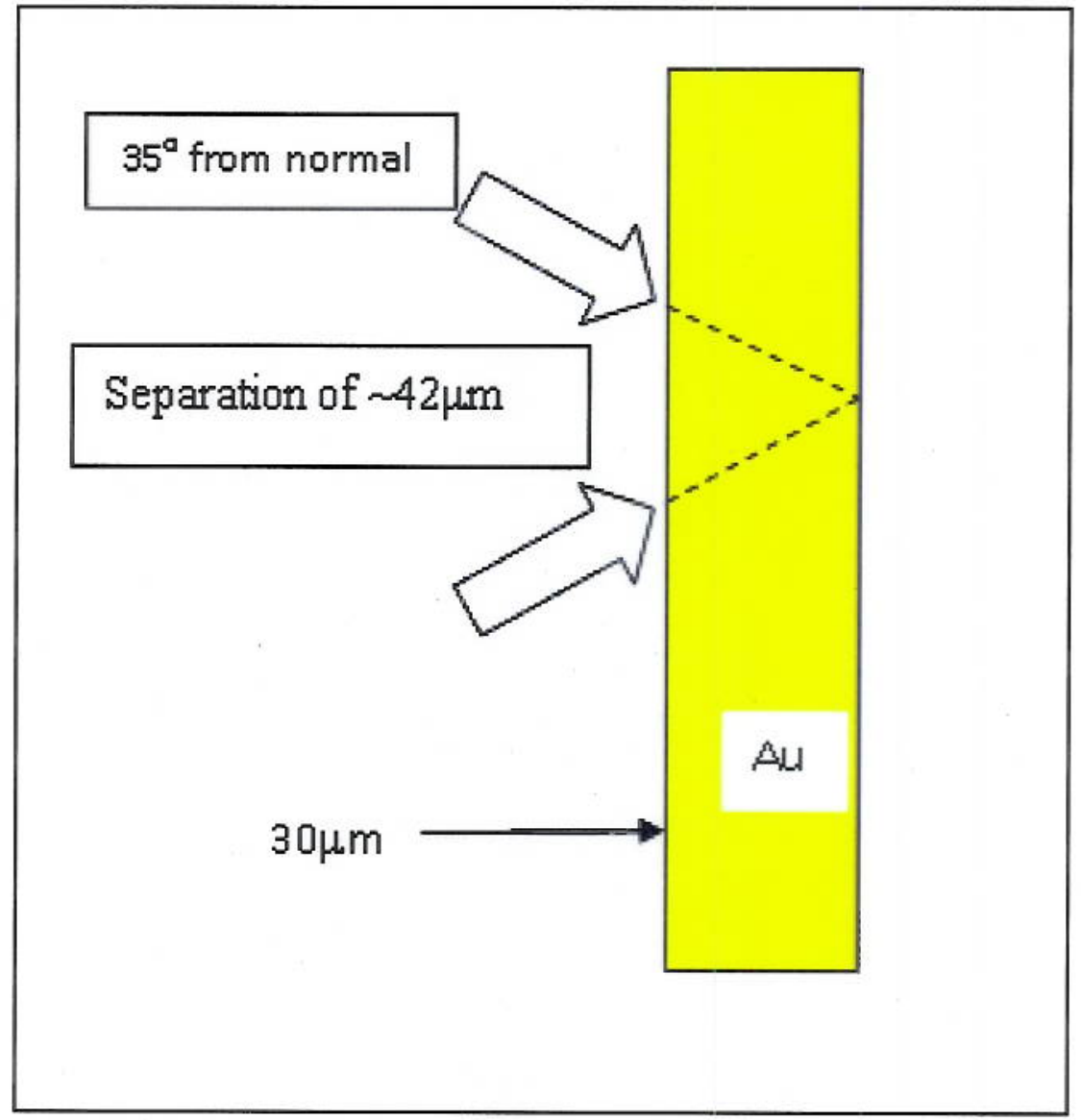


H. D. Shay, LLNL.

LLNL-TR-620154
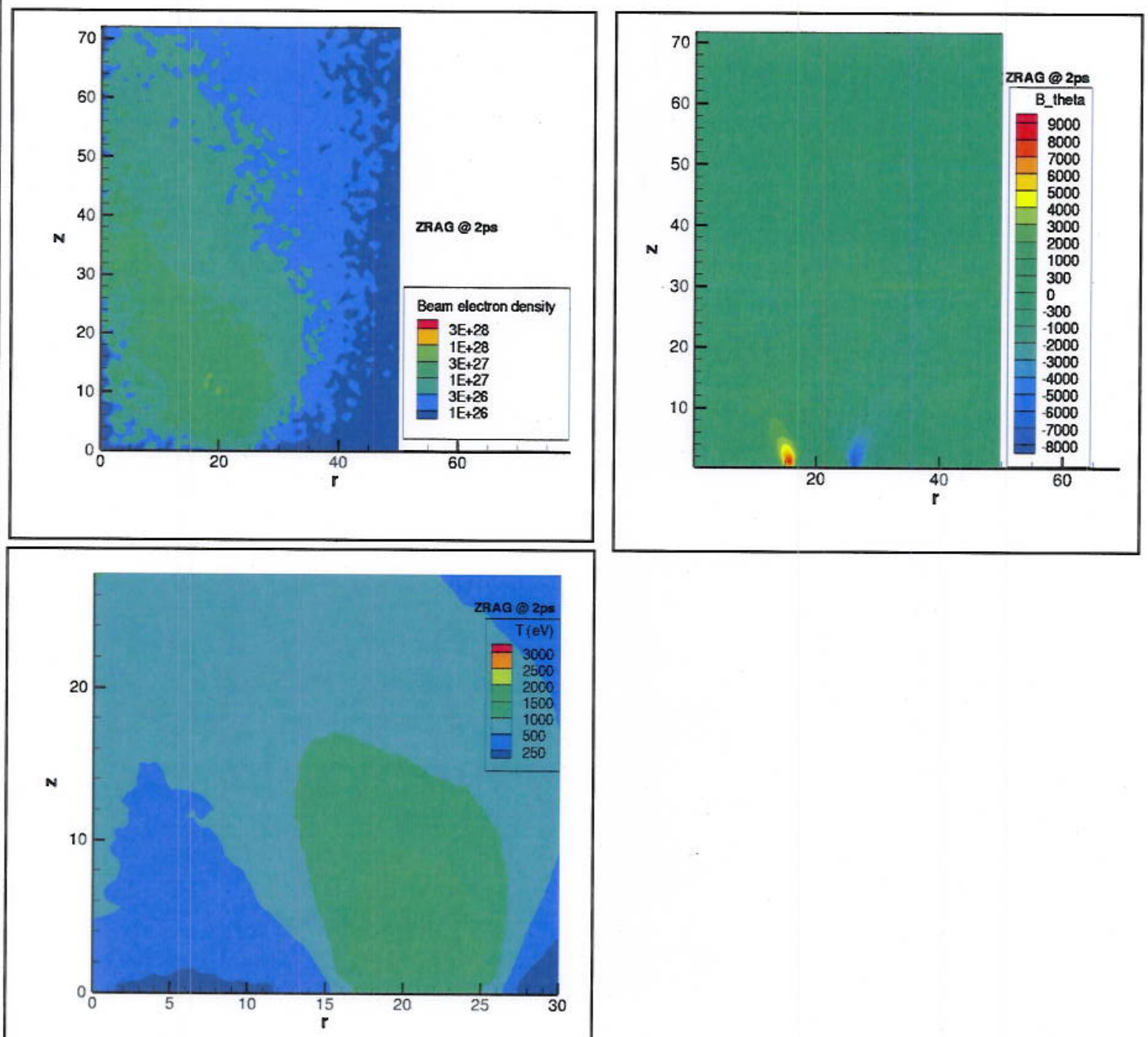

Figure 2 Results of a simulation with $0^{\circ}$ angle of inclination.

The three plots depict the electron density, $B_{\theta}$, and material temperature at $2 \mathrm{ps}$ for electrons launched with $0^{\circ}$ angle of inclination with respect to the axis of symmetry, normal to the surface of the Au foil.

The $2 \mathrm{D}$ axis of symmetry is the vertical $\mathrm{z}$ axis. The spatial units are microns.

The Au foil occupies the volume from $\mathrm{Z}$ of 0 to $30 \mu \mathrm{m}$ and $\mathrm{R}$ of 0 to $50 \mu \mathrm{m}$. The Au foil has density of $19.2 \mathrm{~g} / \mathrm{cc}$.

The units of electron density are $\# / \mathrm{m}^{3}$, and the units of $B_{\theta}$ are tesla. 


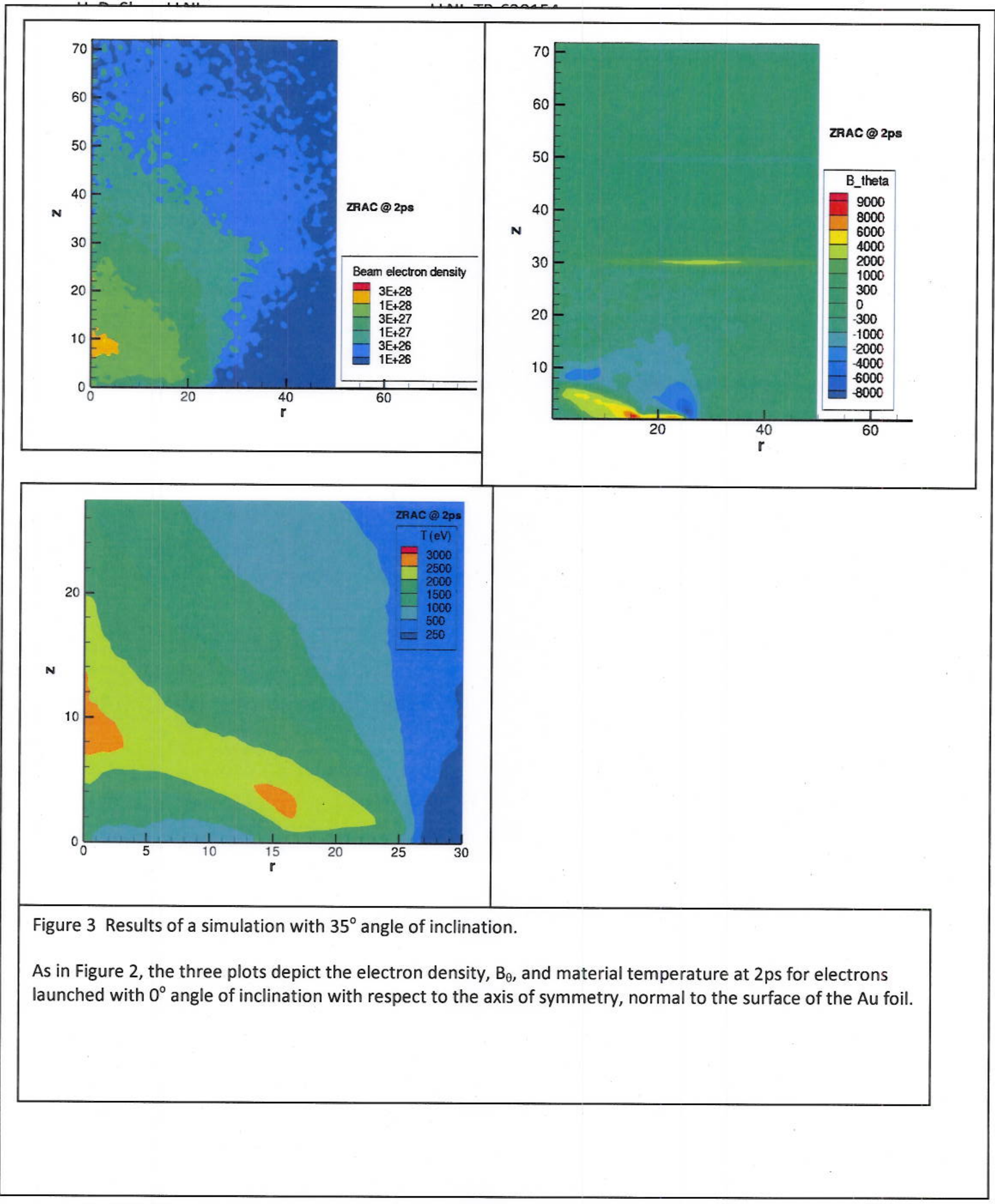



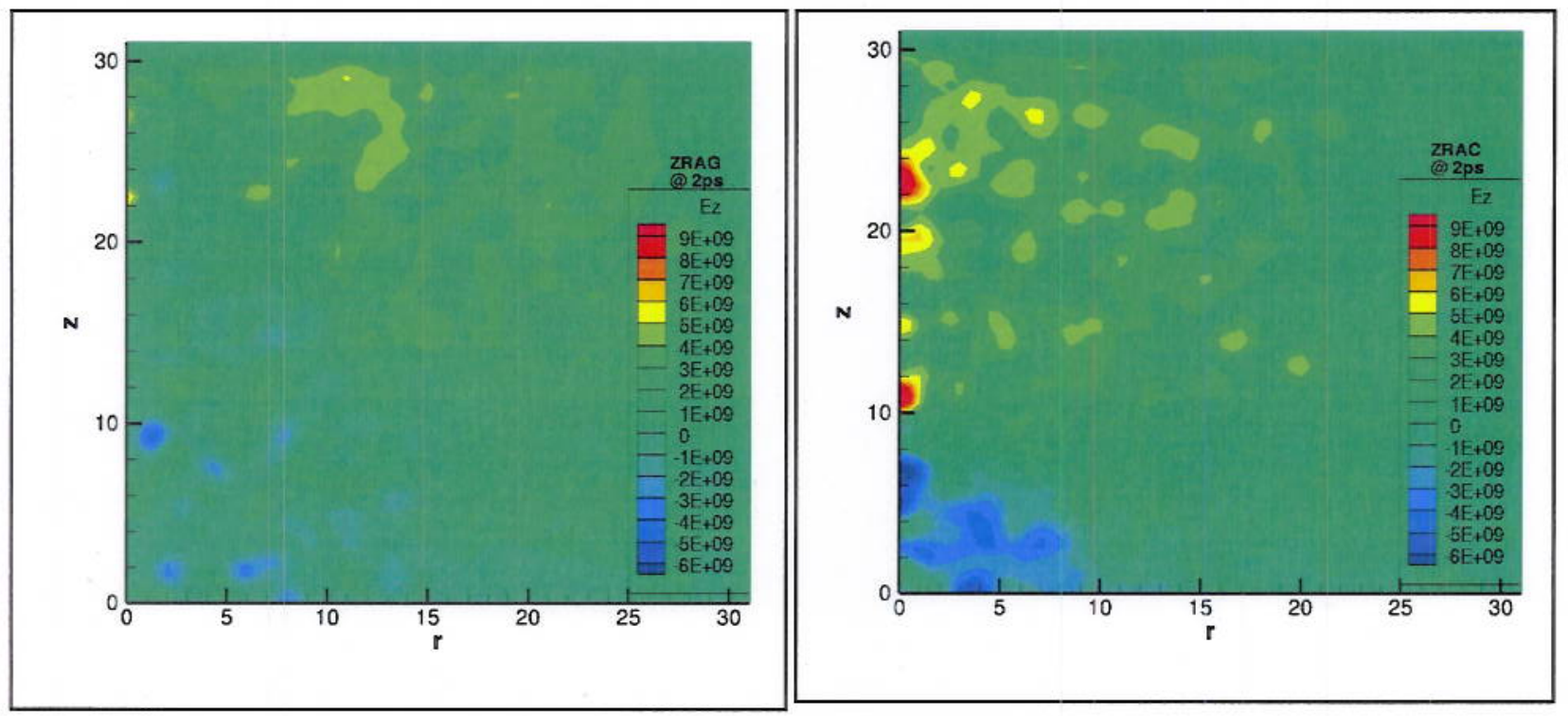

Figure 4

These two plots show $E_{z}$ at $2 p s$ for annular beams with $0^{\circ}$ (ZRAG) and $35^{\circ}$ (ZRAC) angle of incidence. The units of the electric field are $\mathrm{V} / \mathrm{m}$. 